\title{
Polyunsaturated Fatty Acid Metabolism during Lactation
}

\author{
Hans Demmelmair, Thorsten Sauerwald, Nataša Fidler, Margarethe \\ Baumheuer, Berthold Koletzko
}

Division of Metabolic Disorders and Nutrition, Dr. von Haunersches Kinderspital, University of Munich, Germany

Breast milk is the ideal diet for healthy infants and provides a balanced supply of nutrients for at least the first 4-6 months of life [1]. Most of the energy content of breast milk is contributed by milk fat, which contains fatty acids available from diet, from body stores and from endogenous synthesis [2]. Longchain fatty acids mainly originate from the diet, either directly or after intermediate incorporation into body stores. After their absorption, dietary long-chain fatty acids are reesterified in triacylglycerols in the intestinal mucosa and enter the circulation in the form of chylomicrons which are available for uptake by the mammary gland. In the fasting state, triacylglycerols are transported from the liver as very-low-density lipoproteins into the mammary gland. In several studies, it has been shown that human milk fatty acid composition is altered by different diets and by dietary supplementation with selected fatty acids [3, 4].

The finding that in lactating women the overall fat mobilization from adipose tissue tends to exceed fat accretion supports the importance of body stores for milk fat synthesis [5]. Martin et al. [6] found a significant correlation between the linoleic acid (LA) content of white adipose tissue and the content of that fatty acid in colostrum and mature milk, demonstrating the contribution of maternal fat stores to human milk lipids.

Endogenous synthesis must be considered as a source for milk fatty acids, except for the essential fatty acids. A considerable portion of the medium-chain fatty acids is synthesized in the mammary gland, and this is influenced by the carbohydrate content of the maternal diet [7]. While endogenous synthesis seems to be of minor quantitative importance for saturated and monounsaturated longchain fatty acids, endogenous synthesis could be important with respect to the 
long-chain polyunsaturated derivatives of the essential fatty acids (LC-PUFA), namely arachidonic acid (AA) and docosahexaenoic acid (DHA). Vegetarians with marginal dietary intakes of LC-PUFA showed similar LC-PUFA content in breast milk compared to mothers consuming omnivorous diets [8]. Mobilization from body fat or another large endogenous pool of LC-PUFA, which may serve as a substrate source for milk production, might guarantee a more constant supply of LC-PUFA which appear to be of importance for infant development [9].

Quantitative determinations of dietary intake and milk output of a fatty acid cannot distinguish different sources from which milk fatty acids are derived. Rather, the application of stable isotope labeled analogues offers the possibility to elucidate the processes involved in the transfer of a fatty acid into milk either unchanged or as one of its conversion products. Since the use of stable isotope tracers in clinical investigations is safe and without adverse effects even in newborn infants [10], they can be used to study the physiology of substrate flux in lactation.

Hachey et al. [11] applied deuterated fatty acids to breast-feeding women and estimated from their results that only $29 \%$ of palmitic, oleic and linoleic acids incorporated into human milk fat within $72 \mathrm{~h}$ were derived from isotopically labeled dietary fatty acids during late lactation [11]. These findings suggest four major routes for the metabolism of dietary LA in lactating women: oxidation, direct transfer into milk, incorporation into body stores and conversion into metabolites other than $\mathrm{CO}_{2}$. In an attempt to quantify these pathways, we studied the metabolic disposal of dietary LA in 6 healthy lactating women consuming omnivorous diets [12]. All women were breast-feeding one term infant and were studied repeatedly in the 2nd, 6th and 12th week of lactation. During each observation period, they continued their usual dietary habits. At the start of each study period, the women received $1 \mathrm{mg} / \mathrm{kg}$ body weight of uniformly ${ }^{13} \mathrm{C}$ labeled LA as one bolus dose.

Milk samples were obtained during 5 days, starting in the morning of the first study day before tracer application. A total of 15 samples was collected at time points $0,6,12,24,30,36,48,54,60,72,78,84,96,102$ and $108 \mathrm{~h}$ after the tracer intake. Daily milk production was determined by weighing the infant before and after feeding. Breath samples were collected by standard procedures before breakfast on the first study day, in hourly intervals until $12 \mathrm{~h}$ after start, and during the following 4 days at the same time points when milk was sampled. Since it was technically not feasible to perform measurements of total $\mathrm{CO}_{2}$ production, a value of $300 \mathrm{mmol} \mathrm{CO} / \mathrm{m}^{2}$ of body surface per hour was assumed. Quantitative analysis of milk samples was performed as described by GenzelBoroviczény et al. [13]. ${ }^{13} \mathrm{C}$ content of fatty acid methyl esters and exhaled $\mathrm{CO}_{2}$ was analyzed by gas chromatography combustion isotope ratio mass spectrometry with the analytical setup described previously [12]. 
Table 1. Fractional recovery (mean \pm SE) of orally applied ${ }^{13} \mathrm{C}$-LA in 6 lactating women 24 and $108 \mathrm{~h}$ after tracer intake in exhaled $\mathrm{CO}_{2}$ and milk LA, dihomo- $\gamma$-linolenic acid (DGLA) and AA, studied in the 2nd, 6th and 12th week of lactation

\begin{tabular}{lcccc}
\hline & $\begin{array}{l}\text { Time interval } \\
\mathrm{h}\end{array}$ & $\begin{array}{l}\text { Week 2 } \\
\text { \% dose }\end{array}$ & $\begin{array}{l}\text { Week 6 } \\
\% \text { dose }\end{array}$ & $\begin{array}{l}\text { Week 12 } \\
\% \text { dose }\end{array}$ \\
\hline $\mathrm{CO}_{2}$ & 24 & $10.7 \pm 2.4$ & $10.7 \pm 1.8$ & $10.2 \pm 1.7$ \\
Milk LA & 108 & $14.8 \pm 2.6$ & $23.9 \pm 3.7$ & $15.9 \pm 3.5$ \\
& 24 & $5.5 \pm 1.0$ & $5.7 \pm 1.3$ & $5.7 \pm 1.7$ \\
Milk DGLA & 108 & $11.5 \pm 1.7$ & $12.7 \pm 2.5$ & $11.3 \pm 2.5$ \\
& 24 & $0.06 \pm 0.02$ & $0.05 \pm 0.01$ & $0.05 \pm 0.01$ \\
Milk AA & 108 & $0.20 \pm 0.05$ & $0.20 \pm 0.04$ & $0.17 \pm 0.04$ \\
& 24 & $0.01 \pm 0.01$ & n.d. & n.d. \\
& 108 & $0.02 \pm 0.01$ & $0.02 \pm 0.01$ & $0.02 \pm 0.01$ \\
\hline
\end{tabular}

There were no significant effects of the lactational stage (ANOVA; $p>0.05)$. n.d. = Not detectable.

We considered four exit routes for the tracer, namely milk LA, dihomo- $\gamma-$ linolenic acid and AA as well as breath $\mathrm{CO}_{2}$. In table 1, the corresponding recoveries for the first $24 \mathrm{~h}$ and for the whole observation period of $108 \mathrm{~h}$ are presented. It is obvious that a sizeable portion of the tracer (50-80\%) was not recovered with the applied approach. Several reasons need to be considered to explain this unrecovered tracer portion, e.g. incorporation of ${ }^{13} \mathrm{C}$ into other components such as short- and medium-chain fatty acids which were not measured. Furthermore considerable portions of lipid tracers catabolized in energy metabolism are not recovered in breath [14]. Even considering these possible metabolic routes for part of the tracer, it appears probable that a considerable portion of the tracer is also incorporated into large-body pools with slow turnover, resulting in a delayed appearance with low levels of enrichment in the sampled compounds.

The recovery determined after 5 days cannot be ascribed to direct transfer into milk or breath from the diet, as it has to be expected that the label recovered after several days was stored in pools with slow turnover and thus was not transferred directly from the diet. To choose any shorter time interval seems to be somewhat arbitrary and not well justifiable on the grounds of known physiology. For this reason, we have constructed a compartmental model, with 3 body pools for LA, including 1 pool with a slow turnover and no direct flux from this pool into milk or breath [12]. With this model, we calculated a direct transfer of $8.9 \pm$ $1.1 \%$ (mean $\pm \mathrm{SE}$ ) of the tracer into milk LA, if direct transfer is defined as the probability of dietary LA to be excreted into milk without entering the slow 
turnover pool. This result is well within the range defined by the cumulative recoveries after 12 and $108 \mathrm{~h}$.

With respect to the LC-PUFA derivatives, we conclude that the current dietary intake of LA is not the major precursor for milk dihomo- $\gamma$-linolenic acid and AA, since less than $0.3 \%$ of the LA tracer were recovered in its LC-PUFA metabolites. However, this does not exclude dietary LA as a source for milk LCPUFA, because the LA incorporated into body stores may be a precursor for LCPUFA synthesis in maternal tissues. In this case, the body pools of dihomo- $\gamma-$ linolenic acid and AA might well be large enough to introduce a sufficient dilution of the ${ }^{13} \mathrm{C}$-enriched LC-PUFA synthesized from the LA tracer to make it undetectable with the methodology used in our study. In fact, the observed kinetics of AA enrichment in milk, which did not reach a maximum ${ }^{13} \mathrm{C}$ enrichment during the observation period of 5 days, appear to reflect a continued transfer of AA into milk synthesized from ${ }^{13} \mathrm{C}$-labeled LA in maternal tissues.

There was no indication of a relationship between the transfer of labeled LA into milk and dietary LA intake (5-16 g/day). This is in agreement with the reported immediate effect of dietary fatty acid intake on the fatty acid composition of milk [15] and opens the possibility to influence milk fat composition by maternal dietary supplementation.

Therefore, we tested the effect of dietary supplementation with a DHA-rich oil (200 mg DHA/day) on the metabolic partitioning in lactating women. In this study two groups of 5 lactating women each consumed either the DHA-rich oil or a placebo oil without LC-PUFA for 2 weeks from the 4th week of lactation onwards. The supplementation resulted in a markedly different DHA content of the milk at the end of the supplementation period $(0.37$ vs. $0.21 \% \mathrm{w} / \mathrm{w} ; \mathrm{p}<$ 0.001 ). On the 14th day of the intervention period, both groups ingested $2 \mathrm{mg} / \mathrm{kg}$ body weight of the same DHA-rich oil, but uniformly labeled with ${ }^{13} \mathrm{C}$. The recovery of ${ }^{13} \mathrm{CO}_{2}$ in breath during $48 \mathrm{~h}$ after tracer intake was identical in both groups (15.4 vs. 15.6\%; DHA-rich oil vs. placebo) [16]. Also, the cumulative recovery of DHA in milk was not significantly different between groups (9.1 vs. 8.0\%) [17]. Thus, an increased intake of DHA in lactating women does not down-regulate DHA transfer into milk and is an effective way to enhance milk DHA levels.

Although maternal diet clearly affects the composition of human milk, these studies using stable isotope methodology show that only a minor proportion of dietary fatty acids is directly transferred into milk, whereas maternal body pools are the major contributors to milk fatty acids, including PUFA and LC-PUFA. Hence, short-term variations of dietary fat composition are buffered to some extent by intermediate incorporation into storage pools, and the PUFA and particularly LC-PUFA content in human milk as well as the supply to the breastfed infant remains relatively constant [18]. It is tempting to speculate that this 
metabolic buffer benefits the breast-fed infant by reducing the variability in dietary supply of these essential substrates with great biological relevance for early human development. Part of the maternal dietary fatty acid intake, however, is directly transferred into milk, probably without significant influence of dietary intake in the tested ranges. This enables the possibility to influence milk fat composition by supplementing the diet of lactating mothers.

\section{Acknowledgments}

The work presented here was financially supported in part by Deutsche Forschungsgemeinschaft, Bonn, Germany (KO 912/5-1). Part of the tracer material was provided as a gift by Martek Biosciences Corp, Columbia, USA.

\section{References}

1 Rodriguez-Palmero M, Koletzko B, Kunz C, Jensen R: Nutritional and biochemical properties of human milk. Part II. Lipids, micronutrients, and bioactive factors. Clin Perinatol 1999;26:359.

2 Koletzko B, Rodriguez-Palmero M: Polyunsaturated fatty acids in human milk and their role in early infant development. J Mammary Gland Biol Neoplasia 1999;4:269-284.

3 Henderson RA, Jensen RG, Lammi-Keefe CJ, Ferris AM, Dardick KR: Effect of fish oil on the fatty acid composition of human milk and maternal and infant erythrocytes. Lipids 1992;27:863-869.

4 Koletzko B, Thiel I, Abiodun PO: The fatty acid composition of human milk in Europe and Africa. J Pediatr 1992;120:S62-S70.

5 Rebuffé-Scrive M, Enk L, Crona N, Lönnroth P, Abrahamsson L, Smith U, Björntorp P: Fat cell metabolism in different regions in women. J Clin Invest 1985;75:1973-1976.

6 Martin JC, Bougnoux P, Fignon A, Theret V, Antoine J-M: Dependence of human milk essential fatty acids on adipose stores during lactation. Am J Clin Nutr 1993;58:653-659.

7 Koletzko B, Thiel I, Abiodun PO: Fatty acid composition of mature human milk in Nigeria. Z Ernährungwiss 1991;30:289-297.

8 Sanders TAB, Reddy S: The influence of a vegetarian diet on the fatty acid composition of human milk and the essential fatty acid status of the infant. J Pediatr 1992;120:S71-S77.

9 Koletzko B, Diener U, Fink M, Berghaus T, Demmelmair H, von Schönaich P, Bernsau U: Supply and biological effects of long-chain polyunsaturated fatty acids (LCPUFA) in premature infants; in Ziegler E, Lucas A, Moro G (eds): Nutrition of the Extremely Low Birthweight Infant. Philadelphia, Lippincott-Raven, 1999, pp 33-48.

10 Koletzko B, Sauerwald T, Demmelmair H: Safety of stable isotope use. Eur J Pediatr 1997;156:S12-S17.

11 Hachey DL, Thomas MR, Emken EA, Garza C, Brown-Booth L, Adlof RO, Klein PD: Human lactation: maternal transfer of dietary triglycerides labeled with stable isotopes. J Lipid Res 1987;28:1185-1192.

12 Demmelmair H, Baumheuer M, Koletzko B, Dokoupil K, Kratl G: Metabolism of U- ${ }^{13} \mathrm{C}$ labeled linoleic acid in lactating women. J Lipid Res 1998;39:1389-1396.

13 Genzel-Boroviczény O, Wahle J, Koletzko B: Fatty acid composition of human milk during the 1st month after term and preterm delivery. Eur J Pediatr 1997;156:142-147.

14 Sidossis LS, Coggan AR, Gastaldelli A, Wolfe RR: Pathway of free fatty acid oxidation in human subjects - Implications for tracer studies. J Clin Invest 1995;95:278-284. 
15 Francois CA, Connor SL, Wander RC, Connor WE: Acute effects of dietary fatty acids on the fatty acids of human milk. Am J Clin Nutr 1998;67:301-308.

16 Fidler N, Sauerwald T, Demmelmair H, Pohl A, Koletzko B: Oxidation of an oil rich in docosahexaenoic acid compared to linoleic acid in lactating women. Ann Nutr Metab 1999;43:339-345.

17 Fidler N, Sauerwald T, Pohl A, Demmelmair H, Koletzko B: Docosahexaenoic acid transfer into human milk after dietary supplementation: A randomised trial. J Lipid Res 2000;41: $1376-1383$.

18 Koletzko B, Demmelmair H, Socha P: Nutritional support of infants and children: Supply and metabolism of lipids. Ballieres Clin Gastroenterol 1998;12:671-696.

Prof. Berthold Koletzko, MD

Division Metabolic Disorders and Nutrition, Dr. von Haunersches Kinderspital

University of Munich, Lindwurmstrasse 4, D-80336 München (Germany)

Tel. +49 8951603486 , Fax +498951603336

E-Mail Berthold.Koletzko@kk-i.med.uni-muenchen.de 